\title{
Knowledge, attitude and practice of Lebanese primary care physicians in nutrition counseling: a self-reported survey
}

\author{
Rasha A. Hseiki, Mona H. Osman, Rana T. El-Jarrah, Ghassan N. Hamadeh and Najla A. Lakkis \\ Department of Family Medicine, American University of Beirut Medical Center (AUB-MC), Beirut, Lebanon
}

\begin{abstract}
Aim: This study aims to assess the knowledge, attitude and practice of primary care physicians (PCPs) in Lebanon regarding nutrition counseling and to investigate possible related barriers. Background: Nutrition counseling is an important aspect of patient care, especially with the increase in nutrition-related disorders. Methods: This is a descriptive study among a convenience sample of PCPs in Lebanon at two annual conferences in 2014 using an anonymous questionnaire. Findings: Response rate was $54.6 \%$. Overall, physicians considered that they have good to very good nutritional knowledge. Although they rated their formal nutritional education poorly, they had a positive attitude towards nutritional counseling and reported practicing general nutritional counseling with their patients. Barriers to nutritional counseling were: time, perceived poor patient adherence to diet, gap in physician's nutritional knowledge and lack of insurance coverage for dietitian fees. Changes should be made to medical education curricula to include nutrition courses related to prevalent health problems.
\end{abstract}

Key words: family physicians; general practitioners; medical education; nutrition

Received 31 January 2017; revised 9 May 2017; accepted 15 May 2017; first published online 13 June 2017

\section{Background}

The prevalence of nutrition-related disorders, especially complications of overweight and obesity, is on the rise across all ages and socioeconomic groups worldwide (World Health Organization, 2003; 2016; Sebiany, 2013; United States Preventive Services Task Force, 2014). Primary care physicians (PCPs) are a widely consulted source regarding health information (Truswell et al., 2003) and they are more costeffective than dietitians in nutritional counseling (Olsen et al., 2005). Although patients regard PCPs as a reliable and accessible source of nutrition counseling and expect nutritional advice from them (Hiddink et al., 1997), their expectations are

\footnotetext{
Correspondence to: Dr Najla A. Lakkis, Department of Family Medicine, Faculty of Medicine, American University of Beirut, PO Box 11-0236, Riad El Solh, Beirut 1107-2020, Lebanon. Email: ne23@aub.edu.lb
}

not always met (Tham and Young, 2008; Crowley et al., 2012). Several factors have been implicated in that, and some of these barriers include lack of time, lack of physicians' nutritional knowledge, lack of payment and lack of patient adherence to diet (Talip et al., 2003). In fact, it was shown that physicians with better knowledge, more access to resources such as dietitians, and more positive attitude towards nutrition-related problems such as obesity, have better skills in weight management and advice (Rurik et al., 2013).

In Lebanon, the only study available concerning this topic was done by a group of medical students at the American University of Beirut in 1987, as a project for fulfillment of the requirements of a course. It concluded that the second and third year Lebanese medical students' nutritional knowledge was poor and it stressed the importance of improvement in medical curriculum concerning nutrition (Al Amin et al., 1987). No similar study was done for graduate physicians in Lebanon. 
This study targeted PCP because general medicine was found to be most frequently used for consultation in Lebanon in 2012 (Institute of Health Management and Social Protection, 2012), and primary care setting is ideal for opportunistic nutritional advice. PCP is defined here as general practitioners who completed a one-year residency program after their medical school, or family physicians who completed an additional three to four years residency training in family medicine after medical school. We aimed to explore the status of nutritional counseling in primary care in Lebanon by assessing PCPs' knowledge, attitude, and practice in this topic, and investigating their opinion on possible barriers encountered in their practice, so that specific actions can be recommended for improvement. Knowing that through adoption of lifestyle changes, the risk of chronic disease would decrease (Flesher et al., 2011) and that patients who are advised to lose weight by physicians are more likely to do so (Nasreddine et al., 2012), it is important to study physicians' role in nutrition counseling.

\section{Methods}

This descriptive study targeted PCPs who attended General Practitioners' Conference in October 2014 and/or Family Medicine Annual Conference in November 2014, with no exclusion and no duplication. It was a convenient sample, with a total of 251 eligible physicians.

A self-administered anonymous questionnaire was provided to each participant, along with an envelope and an informed consent letter. The estimated time to fill the survey was $10 \mathrm{~min}$. The consent was considered to have been obtained when the physician filled and returned the questionnaire. The questionnaire encompassed items including demographic information and 17 questions with Likert-type scale responses to assess the physician's perceived knowledge $(n=3)$, attitude $(n=3)$, and practice $(n=6)$ regarding nutrition counseling, as well as opinion about possible barriers $(n=5)$ encountered in this practice.

Before the initiation of the study, the approval of the Institutional Review Board (IRB) at American University of Beirut Medical Center was secured.

Data analysis was conducted with frequencies and bivariate analysis using $\chi^{2}$ test in IBM SPSS Statistics 19.

Primary Health Care Research \& Development 2017; 18: 629-634

\section{Results}

\section{Socio-demographic characteristics}

The total number of filled questionnaires was 156. After removing students and non-PCPs, 137 questionnaires were included, out of the 251 eligible physicians, resulting in a $54.6 \%$ response rate. Respondents were distributed equally across most age groups. Males to females ratio was 1.3. The range of years since graduation varied between 1 and 46 years, with $55 \%$ graduates from Lebanese medical schools. Most of the respondents (62\%) were affiliated with an academic institution. Also, it is worth noting that around half of them had a body mass index (BMI) more than 25 , with obesity in $7 \%$ and a nutrition-related health disorder in $22 \%$ (Table 1).

Table 1 Socio-demographic characteristics of the respondents among primary care physicians attending conferences

\begin{tabular}{|c|c|}
\hline Variable & Frequency (\%) \\
\hline \multicolumn{2}{|l|}{ Title of practice } \\
\hline Family physician & $62(46)$ \\
\hline General practitioner & $51(38)$ \\
\hline Family medicine resident & $22(16)$ \\
\hline \multicolumn{2}{|l|}{ Age } \\
\hline $20-29$ years & $30(22)$ \\
\hline $30-39$ years & $28(21)$ \\
\hline $40-49$ years & $34(25)$ \\
\hline $50-59$ years & $24(25)$ \\
\hline 60 years or above & $10(7)$ \\
\hline \multicolumn{2}{|l|}{ Gender } \\
\hline Male & $75(56)$ \\
\hline Female & $60(44)$ \\
\hline \multicolumn{2}{|l|}{ Country of MD graduation } \\
\hline Lebanon & $72(55)$ \\
\hline Outside Lebanon & $59(45)$ \\
\hline \multicolumn{2}{|l|}{ Years since MD graduation } \\
\hline Mean \pm SD & $15.6 \pm 11.4$ \\
\hline Range & $1-46$ years \\
\hline \multicolumn{2}{|c|}{ Affiliation with academic institution } \\
\hline Yes & $81(62)$ \\
\hline No & $49(38)$ \\
\hline \multicolumn{2}{|l|}{ BMI $\left(\mathrm{kg} / \mathrm{m}^{2}\right)$} \\
\hline $\mathrm{BMI}<20$ & $12(9)$ \\
\hline $20 \leqslant \mathrm{BMI}<25$ & $56(42)$ \\
\hline $25 \leqslant \mathrm{BMI}<30$ & $39(29)$ \\
\hline $\mathrm{BMI} \geqslant 30$ & $17(13)$ \\
\hline I don't know & $10(7)$ \\
\hline \multicolumn{2}{|l|}{ Nutrition-related disorder } \\
\hline Yes & $30(22)$ \\
\hline No & $106(78)$ \\
\hline
\end{tabular}

$\mathrm{BMI}=$ body mass index. 


\section{Self-rating of nutritional education and knowledge}

In total, $80 \%$ of the PCPs rated their own nutritional knowledge as good or very good. However, only $60 \%$ rated nutritional education in Continuing Medical Education (CME) as good or very good; and only $50 \%$ rated that of medical school as good or very good. Rating of own nutritional knowledge and of nutritional education received in CME was not associated with any of the studied demographic characteristics; however, rating nutritional education in medical school was significantly associated with the country of medical degree attainment. Physicians graduating from Lebanon rated this knowledge worse than ones who graduated from outside Lebanon $\left(\chi^{2}\right.$ test, $P=0.02)$ (Table 2).

\section{Attitude towards nutritional counseling}

PCPs in this study exhibited a positive attitude towards nutrition, with more than $90 \%$ of them agreeing or strongly agreeing about the impor-

Table 2 Rating of nutritional education and own nutritional knowledge by the respondents among primary care physicians attending conferences

\begin{tabular}{lccc}
\hline Frequency (\%) & $\begin{array}{l}\text { Nutritional } \\
\text { education in } \\
\text { medical school }\end{array}$ & $\begin{array}{l}\text { Nutritional } \\
\text { education } \\
\text { in CME }\end{array}$ & $\begin{array}{l}\text { Own } \\
\text { nutritional } \\
\text { knowledge }\end{array}$ \\
\hline Very poor & $8(5.9)$ & $7(5.2)$ & $1(0.7)$ \\
Poor & $59(43.7)$ & $45(33.3)$ & $24(17.6)$ \\
Good & $45(33.3)$ & $54(40)$ & $70(51.5)$ \\
Very good & $22(16.3)$ & $27(20)$ & $40(29.4)$ \\
Not interested & $1(0.7)$ & $2(1.5)$ & $1(0.7)$ \\
in nutrition & & & \\
\hline
\end{tabular}

$\mathrm{CME}=$ Continuing Medical Education. tance of nutrition, the effectiveness of counseling, and the fact that it is their responsibility to do so. There was no statistical association between any of the three attitude statements' rating with respect to any of the studied demographic characteristics or to the physicians' rating of their own nutritional knowledge (Table 3).

\section{Current practices in nutritional counseling}

PCPs self-reported practicing general nutritional skills such as offering advice and asking about dietary intake in most to all patients. More detailed skills such as teaching patients how to read nutritional labels were less common. Around half of respondents reported referring most to all patients to a dietitian if they have a nutritionrelated disorder. Correlation between self-rating of knowledge and practices showed that physicians who had better rating of their own nutritional knowledge asked more patients about dietary intake as preventive strategy $\left(\chi^{2}\right.$ test, $\left.P=0.00\right)$ and taught more patients how to read a nutrition facts label $\left(\chi^{2}\right.$ test, $\left.P=0.00\right)$. In addition, physicians who considered nutrition counseling as one of their responsibilities offered more nutritional advice $\left(\chi^{2}\right.$ test, $\left.P=0.04\right)$ and referred more patients to dietitians if they have nutrition-related disorder $\left(\chi^{2}\right.$ test, $\left.P=0.00\right)$ (Table 4$)$.

\section{Barriers to nutritional counseling}

Around $62 \%$ of PCPs thought that lack of time was a barrier, while around $72 \%$ thought that the problem was patients' poor adherence to dietary advice. On the other hand, only around half of the respondents considered a gap in physician's knowledge or lack of insurance coverage for dietitian fees as potential barriers. It is worth noting

Table 3 Attitude of the respondents among primary care physicians attending conferences towards nutritional counseling

\begin{tabular}{|c|c|c|c|c|c|}
\hline \multirow[b]{2}{*}{ Statement } & \multicolumn{5}{|c|}{ Responses frequency (\%) } \\
\hline & $\begin{array}{l}\text { Strongly } \\
\text { disagree }\end{array}$ & Disagree & Neutral & Agree & $\begin{array}{l}\text { Strongly } \\
\text { agree }\end{array}$ \\
\hline $\begin{array}{l}\text { Nutrition is important in prevention and } \\
\text { progression of many diseases }\end{array}$ & $6(4.5)$ & $0(0)$ & $1(0.7)$ & $45(33.6)$ & $82(61.2)$ \\
\hline $\begin{array}{l}\text { Nutrition counseling in primary care is effective } \\
\text { in changing patients' behavior }\end{array}$ & $3(2.3)$ & $1(0.8)$ & $8(6)$ & $68(51.1)$ & $53(39.8)$ \\
\hline $\begin{array}{l}\text { Counseling patients about nutrition is one of my } \\
\text { responsibilities }\end{array}$ & $4(3)$ & $0(0)$ & $7(5.2)$ & $63(47)$ & $60(44.8)$ \\
\hline
\end{tabular}


that physicians who considered lack of time a barrier, referred more patients with nutritionrelated disorders to dietitians $\left(\chi^{2}\right.$ test, $\left.P=0.00\right)$. However, the referral was not associated with the physicians' opinion about gap in nutritional knowledge as a barrier (Table 5).

\section{Discussion}

\section{Summary}

Overall, the surveyed physicians had a good attitude toward nutritional counseling and their selfreported frequency of nutritional practices was acceptable; however, there was still room for improvement in nutritional counseling in general. Their self-perceived nutritional knowledge was overall good but their actual knowledge is unknown. Barriers identified for nutritional counseling were lack of time, gap in physician knowledge, perceived poor patient adherence to dietary advice and lack of coverage of insurance for fees of dietitians.

\section{Strengths and limitations}

This is the first study in Lebanon to explore physicians' status with respect to nutrition.

The results of our study cannot be generalized to all PCPs in Lebanon, because we only targeted physicians in two conferences. There may have also been volunteer bias.

\section{Comparison with existing literature}

In this study, PCPs rated poorly their formal education in nutrition (ie, received in medical school, during residency and in CME), yet considered their nutritional knowledge as good to very good. PCPs seemed to be doing extra effort on their own to enhance their nutritional knowledge, posing a question on their source of information which was not tackled in this study. This perceived gap in nutritional education was also present in other countries. Studies from Western countries such as the United States (Kahn, 2006; Vetter et al., 2008) and Canada (Wynn et al., 2010) and from the Arab gulf countries (Al-Numair, 2004; Al-Zahrani and Al-Raddadi, 2009; Daradkeh et al., 2012)

Table 4 Nutritional practice of the respondents among primary care physicians attending conferences

\begin{tabular}{|c|c|c|c|c|c|}
\hline \multirow[b]{2}{*}{ Own nutritional practice } & \multicolumn{5}{|c|}{ Responses frequency (\%) } \\
\hline & Never & $\begin{array}{l}\text { Minority of } \\
\text { patients }\end{array}$ & $\begin{array}{l}\text { Some } \\
\text { patients }\end{array}$ & $\begin{array}{l}\text { Most } \\
\text { patients }\end{array}$ & $\begin{array}{l}\text { All } \\
\text { patients }\end{array}$ \\
\hline Measure patient's height and weight, and calculate BMI & $6(4.5)$ & $7(5.2)$ & $39(29.1)$ & $54(40.3)$ & $28(20.9)$ \\
\hline $\begin{array}{l}\text { Ask patients about dietary intake as a preventive } \\
\text { strategy }\end{array}$ & $0(0)$ & $7(5.2)$ & $38(28.4)$ & $73(54.5)$ & $16(11.9)$ \\
\hline Offer nutritional advice & $0(0)$ & $3(2.2)$ & $40(29.9)$ & $79(59)$ & $12(9)$ \\
\hline Teach patients how to read a nutrition facts label & 35 (26.5) & $26(19.7)$ & $53(40.2)$ & $15(11.4)$ & $3(2.3)$ \\
\hline Ask patients to do a food diary & $29(21.6)$ & $21(15.7)$ & $57(42.5)$ & $26(19.4)$ & $1(0.7)$ \\
\hline $\begin{array}{l}\text { Refer patients to a dietician if they have a nutrition- } \\
\text { related disorder }\end{array}$ & $1(0.7)$ & $7(5.2)$ & $54(40.3)$ & $55(41)$ & $17(12.7)$ \\
\hline Advise patients to exercise regularly & $0(0)$ & $1(0.7)$ & $11(8.2)$ & $73(54.5)$ & $49(36.6)$ \\
\hline
\end{tabular}

$\mathrm{BMI}=$ body mass index.

Table 5 Opinion of the respondents among primary care physicians attending conferences about barriers to nutritional counseling

\begin{tabular}{|c|c|c|c|c|c|}
\hline \multirow[b]{2}{*}{ Barriers to nutritional counseling } & \multicolumn{5}{|c|}{ Responses frequency (\%) } \\
\hline & Strongly disagree & Disagree & Neutral & Agree & Strongly agree \\
\hline Lack of time & $4(3)$ & $18(13.5)$ & $28(21.1)$ & $69(51.9)$ & $14(10.5)$ \\
\hline Gap in or lack of physician knowledge & $6(4.5)$ & $33(24.8)$ & $28(21.1)$ & $61(45.9)$ & $5(3.8)$ \\
\hline Poor patient adherence to dietary advice & $2(1.5)$ & $15(11.4)$ & $19(14.4)$ & $81(61.4)$ & $15(11.4)$ \\
\hline The fees of a dietician are not covered by insurance & $8(6.1)$ & $21(15.9)$ & $38(28.8)$ & $51(38.6)$ & $14(10.6)$ \\
\hline
\end{tabular}

Primary Health Care Research \& Development 2017; 18: 629-634 
showed that PCPs and physicians-in-training were not very satisfied with their nutritional education and they felt they were not well prepared to give nutritional advice to patients. Moreover, the literature showed bad performance of many PCPs in nutrition quizzes in regional countries including Saudi Arabia (Al-Numair, 2004), Qatar (Daradkeh et al., 2012), Kuwait (Allafi et al., 2013), Iran (Ahmadi et al., 2009) and Turkey (Özçelik et al., 2007). The main fear would be if this was the PCPs actual practice of counseling with wrong nutritional information, taking into consideration that the PCPs in Lebanon for example reported a good quantity of practice in this area.

The identified barriers to nutritional counseling were similar to the ones described by Talip et al. in (2003).

PCPs in this study had a positive attitude towards nutrition, which is consistent with the literature findings (Vetter et al., 2008). The physician's health status (eg, BMI) was not correlated with self-rating of nutritional knowledge or with their attitude toward nutritional counseling. This was similar to a systematic review of the literature that concluded that the physicians' weight status was not found to be significantly correlated to referral or assessment of overweight or obese patients or to their knowledge and skills, considering it part of their duties no matter what their own weight status was (Zhu et al., 2011).

In this study, PCPs also self-reported practicing general nutritional skills such as offering advice and asking about dietary intake in most to all patients. These general nutritional advice lacked detailed information such as teaching patients how to read a nutrition facts label. It was previously shown that physicians were more comfortable discussing general topics in nutrition than those related to chronic disease or special topics such as herbal supplementation (Wynn et al., 2010).

Also in this study, approximately half of respondents self-reported referring most or all patients to dietitians if they had a nutrition-related disorder, which is another aspect of positive PCPs' attitude and practice. Our finding could point out to a better situation in terms of working in multidisciplinary teams, but if physicians depended on referrals, patients who cannot afford multiple fees would not get the chance to get nutritional advice. Even though encouraging referral is a good option, the priority would be to enhance the nutritional knowledge of physicians through well-designed nutrition courses in medical schools, applied nutritional curricula in residency training and mandatory CME nutritional topics. This way, PCPs will be able to provide their patients with accurate targeted nutritional tips and information in a short period of time. Finally, it is important to highlight that the integration of nutrition into medical school curriculum is a continuing challenge worldwide, and different initiatives were started in the United Kingdom and the United States (Ball et al., 2014).

\section{Conclusion}

Patient centered dietary counseling and advice is an integral part of comprehensive primary care. There is a major gap in PCPs' formal nutritional education in Lebanon despite their positive attitude towards nutritional counseling. The central step for improvement in PCPs nutrition knowledge is to have a consensus on the minimum nutritional information that physicians should know, with development of evidence-based practice guidelines for PCPs. Then, there should be changes in curricula of medical schools and residency programs for well-designed comprehensive courses about nutrition, as well as in CME topics for obligatory (non-elective) lectures or workshops in nutrition for PCPs. Other suggestions include adding pamphlets about nutrition in patients' waiting rooms and getting additional paramedical staff (eg, nurses) involved in patients' nutritional counseling. In addition, adding BMI as a vital sign would make it obligatory on the chart, and hence the doctor would be always aware of the patient's weight status as a baseline and for follow up.

\section{Acknowledgments}

None.

\section{Financial Support}

This research received no specific grant from any funding agency, commercial or not-for-profit sectors.

Primary Health Care Research \& Development 2017; 18: 629-634 


\section{Conflicts of Interest}

None.

\section{Ethical standards}

Before the initiation of the study, the approval of the IRB at American University of Beirut Medical Center was secured.

\section{References}

Ahmadi, A., Ershad, M., Givzadeh, H. and Mohammad-Beigi, A. 2009: General physicians' knowledge about nutrition in Shiraz, Iran. Pakistan Journal of Biological Sciences 12, 981-85.

Al Amin, H., Arayssi, T., Birjawi, T., Chatila, W., Doughan, S. and Hubeishy, K. 1987. The need for additional nutritional education in the medical curriculum. Department of Health Services Administration: Lebanese Corner, Saab Medical Library: American University of Beirut.

Allafi, A.R., Alajmi, F. and Al-Haifi, A. 2013: Survey of nutrition knowledge of physicians in Kuwait. Public Health Nutrition 16, 1332-336.

Al-Numair, K.S. 2004: Nutrition knowledge of primary care physicians in Saudi Arabia. Pakistan Journal of Nutrition 3, 344-47.

Al-Zahrani, A.M. and Al-Raddadi, R.M. 2009: Nutritional knowledge of primary health care physicians in Jeddah, Saudi Arabia. Saudi Medical Journal 30, 284-87.

Ball, L., Crowley, J., Laur, C., Rajput-Ray, M., Gillam, S. and Ray, S. 2014: Nutrition in medical education: reflections from an initiative at the University of Cambridge. Journal of Multidisciplinary Healthcare 7, 209.

Crowley, J., Ball, L., Wall, C. and Leveritt, M. 2012: Nutrition beyond drugs and devices: a review of the approaches to enhance the capacity of nutrition care provision by general practitioners. Australian Journal of Primary Health 18, 90-95.

Daradkeh, G.A., Al Bader, K. and Singh, R. 2012: The nutrition knowledge of primary care physicians in the state of Qatar. Pakistan Journal of Nutrition 11, 683.

Flesher, M., Kinloch, K., Grenon, E. and Coleman, J. 2011: Access to dietitians: in primary health care. Canadian Journal of Dietetic Practice and Research 72, 32-36.

Hiddink, G., Hautvast, J., Van Woerkum, C., Fieren, C. and Van't Hof, M. 1997: Consumers' expectations about nutrition guidance: the importance of primary care physicians. The American Journal of Clinical Nutrition 65, 1974S-979S.

Institute of Health Management and Social Protection. 2012: National health statistics report in Lebanon, 2012 edition. Lebanon, Beirut: Saint-Joseph University. Retrieved 1 December 2016 from https://igsps.usj.edu.lb/docs/recherche/ recueil12en.pdf.

Primary Health Care Research \& Development 2017; 18: 629-634
Kahn, R.F. 2006: Continuing medical education in nutrition. The American Journal of Clinical Nutrition 83, 981S-84S.

Nasreddine, L., Naja, F., Chamieh, M.C., Adra, N., Sibai, A.-M. and Hwalla, N. 2012: Trends in overweight and obesity in Lebanon: evidence from two national cross-sectional surveys (1997 and 2009). BMC Public Health 12, 1.

Olsen, J., Willaing, I., Ladelund, S., Jørgensen, T., Gundgaard, J. and Sørensen, J. 2005: Cost-effectiveness of nutritional counseling for obese patients and patients at risk of ischemic heart disease. International Journal of Technology Assessment in Health Care 21, 194-202.

Özçelik, A.Ö., Sürücüoglu, M.S. and Alkan, L. 2007: Survey on the nutrition knowledge level of Turkish physicians: Ankara as a sample. Pakistan Journal of Nutrition 6, 538-42.

Rurik, I., Torzsa, P., Ilyés, I., Szigethy, E., Halmy, E., Iski, G., Kolozsvári, L.R., Mester, L., Móczár, C. and Rinfel, J. 2013: Primary care obesity management in Hungary: evaluation of the knowledge, practice and attitudes of family physicians. BMC Family Practice 14, 156.

Sebiany, A.M. 2013: Primary care physicians' knowledge and perceived barriers in the management of overweight and obesity. Journal of Family and Community Medicine 20, 147.

Talip, W.-A., Steyn, N.P., Visser, M., Charlton, K.E. and Temple, N. 2003: Development and validation of a knowledge test for health professionals regarding lifestyle modification. Nutrition 19, 760-66.

Tham, M. and Young, D. 2008: The role of the general practitioner in weight management in primary care-a cross sectional study in general practice. BMC Family Practice 9, 1.

Truswell, A.S., Hiddink, G.J. and Blom, J. 2003: Nutrition guidance by family doctors in a changing world: problems, opportunities, and future possibilities. The American Journal of Clinical Nutrition 77, 1089S-92S.

United States Preventive Services Task Force. 2014: Final recommendation statement: obesity in adults: screening and management. Retrieved 14 October 2016 from https:// www.uspreventiveservicestaskforce.org/Page/Document/ RecommendationStatementFinal/obesity-in-adults-screeningand-management.

Vetter, M.L., Herring, S.J., Sood, M., Shah, N.R. and Kalet, A.L. 2008: What do resident physicians know about nutrition? An evaluation of attitudes, self-perceived proficiency and knowledge. Journal of the American College of Nutrition 27, 287-98.

World Health Organization. 2003: Diet, nutrition and the prevention of chronic diseases. WHO Technical Report Series. Geneva: World Health Organization.

World Health Organization. 2016: Obesity and overweight fact sheet Retrieved 14 October 2016 from http://www.who.int/ mediacentre/factsheets/fs311/en/ .

Wynn, K., Trudeau, J.D., Taunton, K., Gowans, M. and Scott, I. 2010: Nutrition in primary care: current practices, attitudes, and barriers. Canadian Family Physician 56, e109-116.

Zhu, D., Norman, I. and While, A. 2011: The relationship between doctors' and nurses' own weight status and their weight management practices: a systematic review. Obesity Reviews 12, 459-69. 